\title{
Proteasome Inhibitor Bortezomib: A Double-Edged Sword in Cancer Therapy
}

Azadeh Mehdad and Sônia Maria de Freitas*

Laboratory of Molecular Biophysics, Institute of Biological Sciences, University of Brasilia, Brasilia, Brazil

\begin{abstract}
Asteady flow of reports suggests that proteasome inhibitor bortezomib promotes tumor cell death by degradation of key proteins. Therefore, bortezomib has been gaining intense attention as an anti-neoplastic agent, being the first proteasome inhibitor drug to be used in multiple myeloma's treatment. However, new evidences point to the adverse effects of bortezomib leading to the poor outcome in both hematological and solid tumors. Despite its therapeutic effects, deciphering the molecular mechanisms of bortezomib action as well as the mechanism(s) of resistance to bortezomib in cancer remains a problem to be conquered.
\end{abstract}

Keywords: Proteasome inhibitor; Bortezomib; Cancer

\section{Proteasome Inhibitor Bortezomib: A Double-edged Sword in Cancer Therapy}

The proteasome, from an evolutionary point of view, is ancient and has remained highly conserved in bacteria, yeast, and humans [1]. The proteasome plays an essential role in many important biological processes [2]. As such, disrupting various cell signaling pathways through the proteasome impairment will compromise cell function and survival. Thus, despite of initial doubts due to the crucial role of the proteasome, a wide range of pharmacological proteasome inhibitors has been gaining intense attention as an attractive target for cancer treatment.

Bortezomib (formerly PS-341) is a selective and reversible inhibitor of the chymotrypsin-like activity of the proteasome 26S. The initial idea behind development and use of bortezomib was based on inhibitory effect of bortezomib on the activation of NFkB, through I $\mathrm{B} \alpha$ degradation [3] thereby promoting cell death. However, recent studies evidenced another intracellular target of bortezomib activity suggesting that cytotoxic effect of bortezomib cannot be fully attributed to the inhibition of NFKB activity. In multiple myeloma cell lines, bortezomib has led to the down-regulation of I $\mathrm{B} B a$ and triggering of $\mathrm{NF \kappa B}$ activation, while has increased cytotoxicity [4], suggesting that the ability of proteasome inhibitors to block the activation of NFkB activity may not be a key mechanism of bortezomib-induced cell death in hematopoietic tumors. In the same line, the landmark study of Dolcet and colleagues, demonstrated that bortezomib induces apoptosis in endometrial carcinoma cell lines, but, instead of blocking $\mathrm{NF \kappa B}$, bortezomib increases its transcriptional activity through phosphorylation of IKKa/ $\beta$, degradation of I $\mathrm{B} \alpha$, and phosphorylation of the p65 NFKB [5]. In good agreement, recent investigations have observed that proteasome inhibition by bortezomib increases the nuclear levels of IкB kinase (IKK) in prostate and ovarian cancer cells. As consequence, an increase expression of the pro-inflammatory and pro-angiogenic chemokine interleukin-8 (IL-8) was observed while the expression of other $\mathrm{NF \kappa B}$-regulated genes was suppressed or remains unaffected [6,7].

Besides NFkB, other downstream signaling transduction cascade responsible for the induction of IL- 8 includes p38 MAPK. Recent evidence has shown that prolonged proteasome inhibition led to the activation of p38 MAPK and consequently, overproduction of IL-8; however, inhibition of p38 MAPK attenuated the proteasome inhibition-induced IL-8 release [8]. It is known that IL-8 induces proliferation and survival of cancer cells, potentiates their migration and infiltrates neutrophils at the tumor site. Thus hence, it is plausible to assume that brotezomib-induced IL-8 may represent one of the underlying mechanisms responsible for less effectiveness of brotezomib in solid tumors. Because bortezomib acts in a tumor-type context, further investigations are warranted to verify whether IL-8 suppression has important implications for cancer prognosis and treatment.

Notwithstanding the excellent anti-myeloma activity of brotezomib, emerging evidence raise serious concerns about adverse long-term outcomes of bortezomib therapy including peripheral neuropathy [9], neurotoxicity [10], and acute interstitial nephritis [11]. The data thus far, in both hematological and solid tumors, show that bortezomib is an active agent. Nonetheless, single-agent bortezomib therapy clearly has various limitations. In addition, our knowledge of the mechanism underlying brotezomib-induced adverse effects is very limited. Apart from bortezomib treatment modification, discontinuation or withdrawal, no efficient prevention or therapeutic strategy has been implemented.

Therefore, the better understanding of mechanisms involved in bortezomib-induced pleiotropic effects will help to delineate the role of bortezomib alone or in combination with other therapies. Further experimental studies as well as clinical trials are essential in order to boost the efficacy of treatment with bortezomib and improve patient's quality of life.

\section{Acknowledgements}

This work was supported by Concelho Nacional de Desenvolvimento Científico e tecnológico, Coordenação de Aperfeiçoamento de Pessoal de Nível Superior (CAPES) and Fundação de Apoio à Pesquisa do Distrito Federal (FAPDF).

*Corresponding author: Sonia Maria de Freitas, Laboratory of Molecular Biophysics, Institute of Biological Sciences, Block J, 2nd Floor, University of Brasilia, Asa norte, Brasília, DF-70910-900, Brazil, Tel: +556181169539; E-mail: nina@unb.br (or) azadehmehdad@gmail.com

Received September 30, 2016; Accepted October 12, 2016; Published October 15,2016

Citation: Mehdad A, Freitas SM (2016) Proteasome Inhibitor Bortezomib: A Double-Edged Sword in Cancer Therapy. Med Chem (Los Angeles) 6: 640-641. doi:10.4172/2161-0444.1000407

Copyright: @ 2016 Mehdad A, et al. This is an open-access article distributed under the terms of the Creative Commons Attribution License, which permits unrestricted use, distribution, and reproduction in any medium, provided the original author and source are credited. 
Citation: Mehdad A, Freitas SM (2016) Proteasome Inhibitor Bortezomib: A Double-Edged Sword in Cancer Therapy. Med Chem (Los Angeles) 6: 640-641. doi:10.4172/2161-0444.1000407

\section{References}

1. Adams $\mathrm{J}(2003)$ The proteasome: structure, function, and role in the cell. Cancer Treat Rev 29 Suppl 1: 3-9.

2. Tu Y, Chen C, Pan J, Xu J, Zhou ZG, et al. (2012) The Ubiquitin Proteasome Pathway (UPP) in the regulation of cell cycle control and DNA damage repair and its implication in tumorigenesis. Int J Clin Exp Pathol 5: 726-738.

3. Hideshima T, Richardson P, Chauhan D, Palombella VJ, Elliott PJ, et al. (2001) The proteasome inhibitor PS-341 inhibits growth, induces apoptosis, and overcomes drug resistance in human multiple myeloma cells. Cancer research 61: $3071-3076$

4. Hideshima T, Ikeda H, Chauhan D, Okawa Y, Raje N, et al. (2009) Bortezomib induces canonical nuclear factor-kappaB activation in multiple myeloma cells. Blood 114: 1046-1052.

5. Dolcet X, Llobet D, Encinas M, Pallares J, Cabero A, et al. (2006) Proteasome inhibitors induce death but activate NF-KB on endometrial carcinoma cell lines and primary culture explants. Journal of Biological Chemistry 281: 2211822130 .

6. Manna S, Singha B, Phyo SA, Gatla HR, Chang TP, et al. (2013) Proteasome inhibition by bortezomib increases IL-8 expression in androgen-independent prostate cancer cells: the role of IKKa. The Journal of Immunology 191: 2837-2846.

7. Singha B, Gatla HR, Manna S, Chang TP (2014) Sanacora SProteasome inhibition increases recruitment of IkappaB kinase beta (IKKbeta), S536P-p65, and transcription factor EGR1 to interleukin-8 (IL-8) promoter, resulting in increased IL-8 production in ovarian cancer cells. J Biol Chem 289: 2687-2700.

8. Sanacora S, Urdinez J, Chang TP, Vancurova I (2015) Anticancer drug bortezomib increases interleukin-8 expression in human monocytes. Biochem Biophys Res Commun 460: 375-379.

9. Argyriou AA, Iconomou G, Kalofonos HP (2008) Bortezomib-induced periphera neuropathy in multiple myeloma: a comprehensive review of the literature. Blood 112: 1593-1599.

10. Treon SP, Hunter ZR, Matous J, Joyce RM, Mannion B, et al. (2007) Multicenter clinical trial of bortezomib in relapsed/refractory Waldenstrom's macroglobulinemia: results of WMCTG Trial 03-248. Clinical Cancer Research 13: $3320-3325$

11. Cheungpasitporn W, Leung N, Rajkumar SV, Cornell LD, Sethi S, et al. (2015) Bortezomib-induced acute interstitial nephritis. Nephrol Dial Transplant 30: 1225-1229. 